\title{
A Theoretical Study for Supporting an Autonomous Diesel Power Plant with a Photovoltaic Generator
}

\author{
M. Sylos Labini ${ }^{1}$, G. Delvecchio ${ }^{2}$, F. Fraccalvieri ${ }^{1}$, F. Neri $^{1}$ and B. Valenzano ${ }^{1}$ \\ ${ }^{1}$ Department of Electrotechnics and Electronics - Polytechnic of Bari \\ Via E. Orabona 4 - 70125 Bari (Italy) \\ phone: +39080 5963256, fax: +39080 5963410, e-mail: sylos@poliba.it \\ ${ }^{2}$ Technical Area - University of Bari \\ Piazza Umberto I n.1 , 70100 Bari (Italy) \\ phone:+39 080 5714648, fax:+39 080 5714655, e-mail: g.delvecchio@area-tecnica.uniba.it
}

\begin{abstract}
In consideration of the existing configuration of the Italian electrical market and the need to increase the electrical production due to renewable sources, this paper deals with a technical, economic feasibility study of a photovoltaic plant which can support the diesel electric power plant now existing on the Tremiti Islands (South Italy).
\end{abstract}

This study has been ordered by the electric power producer of the above-mentioned islands.

Key words: Photovoltaic generator, Green Certificates.

\section{Introduction}

In the last years the value of the electric production on the Tremiti Islands has been equal to about $2.8 \mathrm{GWh}$ a year. According to the Italian laws in force, these values do not require the producer to generate energy by renewable sources or, as an alternative, to buy Green Certificates $(G C)$.

Since Italy, within the framework of the EU directives, has complied with the targets set by the Kyoto Protocol for reducing carbon dioxide $\left(\mathrm{CO}_{2}\right)$ emissions and greenhouse gases, small producers, too, will have to generate a part of the energy by renewable sources fuelled plants or to buy an adequate number of Green Certificates. This is why the above producer of the Tremiti Islands has required the Authors to make a technical, economic feasibility study.

\section{The calculation programs carried out}

A first calculation program has been defined. It is entirely general and allows the dimensioning of any photovoltaic plant. The input data are the climatic characteristics of the site under examination and the total amount of energy to produce in a year. The program also allows the determination of the cost of the photovoltaic plant, referring to the existing market prices.

A second calculation program has also been defined so as to assess the various economic indices which give the profitability of the investment by taking into account the cash flows relating to the economic life of the investment.
The cash flows here considered are the following: cost of the photovoltaic plant, saving of fuel, and any possible saving in not having bought Green Certificates.

In order to assess the investment advantage the Authors have employed "simple methods", that is methods that take account of the coming cash flows, and "exact methods" which, on the contrary, take account of the cash flows that follow one another over the time; the latter are calculated by their updating at the moment in which we want to realize the investment.

\section{The first calculation program}

As previously said the program carries out the preliminary dimensioning of the plant and, then, it estimates its cost.

The climatic characteristics of the place under examination are first of all determined. Since we don't have standard climatic data for calculating the annual average radiation on a horizontal plane for the Tremiti Islands, we have resorted to the following standards: UNI 10349, UNI 8477.

These standards use the climatic data of the two places nearer to the area under study and define them as reference places, so the standards give the climatic data by means of interpolating formulas.

After having determined the radiation on a horizontal plane a program carried out by ENEA (National Agency of Alternative Energy) has been used to get the annual average solar energy $(H)$ received from panels having a southern exposure and inclined at an angle of 30 degrees with respect to the horizontal plane $\left(H=1550 \mathrm{kWh} / \mathrm{m}^{2}\right)$.

\section{A. Dimensioning of the photovoltaic plant}

Once the climatic data of the place have been got we have passed to the real dimensioning of the plant. Having chosen the quantity of energy $E_{g}$ that the photovoltaic generator must produce in a year, we have got the minimum surface occupied by the panels by means of the formula:

$$
A_{g}=\frac{E_{g}}{\eta_{g} \times H \times k_{g}}
$$


where:

$A_{g}=$ minimum area of the photovoltaic generator $\left(\mathrm{m}^{2}\right)$

$E_{g}=$ energy which the photovoltaic generator must produce in a year $(\mathrm{kWh})$

$H=$ annual average solar energy $\left(\mathrm{kWh} / \mathrm{m}^{2}\right)$

$\eta_{g}=$ overall efficiency of the photovoltaic generator $(10 \%)$

$k_{g}=$ operational efficiency of the generator $(75 \%$ days of operation in a year).

Once the minimum surface occupied by the panels has been got, we have determined the peak power of the photovoltaic generator according to the formula:

where:

$$
P=A_{g} \times D_{\text {pan }}
$$

$D_{\text {pan }}=$ power density of the panels $(0.130$

$\left.\mathrm{kWp} / \mathrm{m}^{2}\right)$;

$P=$ peak power of the generator $(\mathrm{kWp})$.

The number of panels has also been determined according to the formula:

$$
N=\frac{A_{g}}{A_{\text {pan }}}
$$

where:

$$
A_{p a n}=\text { area of one photovoltaic panel }\left(\mathrm{m}^{2}\right) .
$$

\section{B. Determination of the photovoltaic generator cost}

The net cost of the photovoltaic generator $C_{t o t}$ has finally been determined, with reference to the prices published by ENEA.

With regard to this an average price of $8000 € / \mathrm{kWp}$ installed (referred to as $C_{u n i t}$ ) has been considered. Consequently, the investment cost has been estimated as:

$$
C_{\text {tot }}=P \times C_{\text {unit }}
$$

A percentage of the state incentives coming from some national programs has been then subtracted from this cost by a decrease factor $k_{s i}$. Moreover, an amount due to the decrease in the cost of the photovoltaic technology has been subtracted by a decrease factor $k_{t}$. In this way we have determined the total cost of the investment supported by the power producer, this cost being considered as the expenditure at time zero in the economic analysis according to the following formula:

$$
C_{0}=C_{t o t} \times k_{t} \times\left(1-k_{s i}\right)
$$

where:

$C_{0}=$ cost supported by the power producer $(€)$;

$k_{t}=$ factor of decrease in technology;

$k_{s i}=$ factor of state incentives.

\section{Definitions on the economic analysis}

Before explaining the methods used for the analysis of the investments it is useful to recall some definitions on the economic analysis:

- The Net Cash Flow $(N C F)$ which represents the algebraic sum of all the money transactions occurring in a hypothetical "cash" during a generic period (year); it is determined on the basis of the current values taken by the proceeds and by the costs due to the investment.

- The time horizon, that is the time in which the analysis must be extended. We suppose that this time is equal to $n=20$ years, this being the working life of this technology.

It is possible to represent the time arrangement of the net cash flows $(N C F)$ by a time-financial diagram, as shown in Fig. 1.

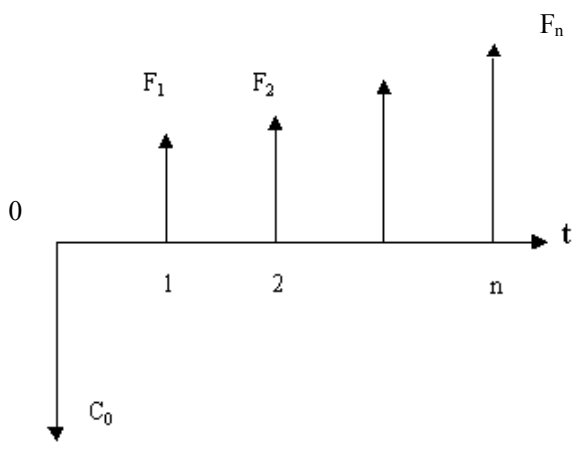

Fig. 1. Time-financial diagram

where:

$n=$ working life of the technology (years);

$C_{0}=$ cost supported by the power producer $(€)$;

$F_{k}=$ cash flows coming from the investment in the $k^{\text {th }}$ year $(€)$.

\section{The second calculation program}

The second part of the program takes into account some functions and economic indices to determine the return on the investment.

The following two methods of evaluation under deterministic state are taken into consideration:

- The Pay Back Period $(P B P)$ which gives information on the time needed for recovering the invested capital; its formula is here given:

$$
P B P=\min _{[0, n]}\{p\} \quad \ni^{\prime} \quad \sum_{k=1}^{p} F_{k}-C_{0} \geq 0
$$

where:

$C_{0}=$ cost supported by the power producer $(€)$; $F_{k}=$ cash flows coming from the investment in the $k^{\text {th }}$ year $(€)$.

- The Net Present Value (NPV) gives information on the economic profit of the investment. If NPV is positive there is an economic, financial advantage. Here is its formula:

$$
N P V=\sum_{k=1}^{n} \frac{F_{k}}{(1+i)^{k}}-C_{0}
$$


where:

$C_{0}=$ cost supported by the power producer $(€)$;

$F_{k}=$ cash flows coming from the investment in the $k^{\text {th }}$ year $(€)$;

$n=$ working life of this technology (years);

$i=$ interest rate.

\section{A. The net cash flows examined}

The net cash flows (NCF) referred to as $F_{k}$ in the previous formulas are of two types (subscript $k$ will be later omitted):

- Annual saving of fuel:

where:

$$
S_{f}=E_{g} \times C_{f u e l} \times q
$$

$E_{g}=$ energy which the photovoltaic generator must produce in a year $(\mathrm{kWh})$; $C_{\text {fuel }}=$ unit cost of diesel fuel $(€ / l)$; $q=$ consumption of fuel per $\mathrm{kWh}(l / \mathrm{kWh})$.

- Saving $S_{G C}$ due to the production of energy coming from renewable source and so saving due to the nonpurchase of the Green Certificates. This saving, which occurs only if the producer is obliged by the law to use renewable sources, is given by:

where:

$$
S_{G C}=C_{G C} \times E_{g}
$$

$C_{G C}=$ unit price of the Green Certificates $(€ / \mathrm{kWh})$;

$E_{g}=$ energy which the photovoltaic generator must produce in a year $(\mathrm{kWh})$

NCFs, referred to as $F_{k}$ in the formulas above and in Fig. 1 , are equal only to $S_{f}$ if the producer is not obliged to buy Green Certificates, otherwise they are equal to the sum of $S_{f}$ and $S_{G C}$.

\section{The electric power plant of the Tremiti Islands}

At present all the electric power on the Tremiti Islands is produced by 5 diesel generators, each one having a power equal to $800 \mathrm{kVA}$ (see Fig. 2).

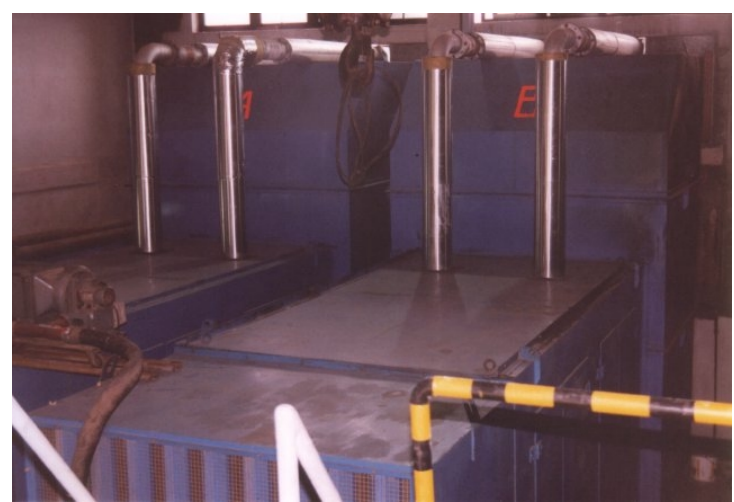

Fig. 2. Diesel generators

The area used as electric power generation plant is $3.232 \mathrm{~m}^{2}$, it contains diesel generators, voltage trans- formers, medium-voltage switchboard (see Fig. 3), transformer room $\mathrm{MT} / \mathrm{bt}$, offices and shop.

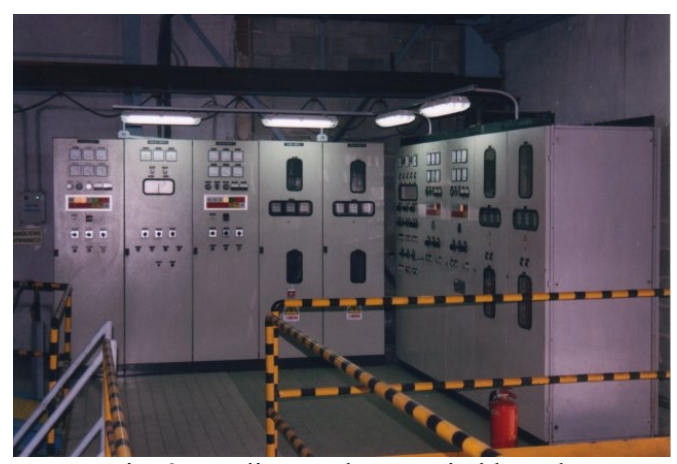

Fig. 3. Medium-voltage switchboards

The energy supply occurs through an almost entirely buried grid, in consideration of the high landscape value, except for the air connection between the two islands (see Fig. 4).

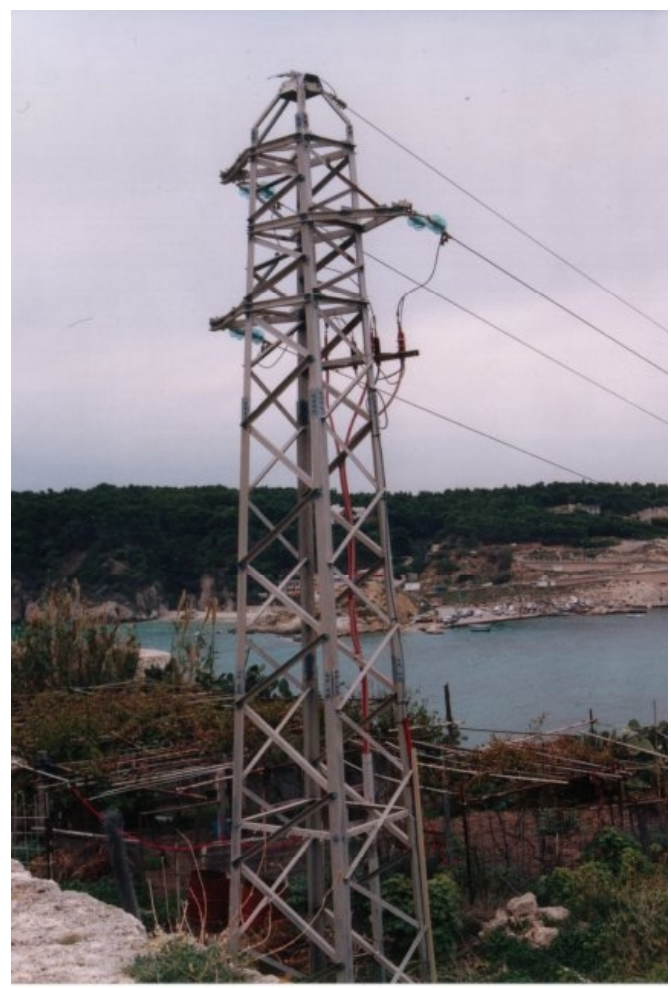

Fig. 4. Air connection between the two islands

Moreover, the electric production is equal to about $2.8 \mathrm{GWh}$ a year.

The fuel average consumption needed for producing $1 \mathrm{kWh}$ has been obtained from both Technical Data of engines and measurements taken during their operation. This value has been fixed at $0.33 l / \mathrm{kWh}$.

\section{The technical, economic feasibility study}

Starting from the annual average production of electric power of the Tremiti Islands, that is about $2.8 \mathrm{GWh}$, for the simulations we have assumed that the photovoltaic plant must be dimensioned to produce $E_{g}=0.28 \mathrm{GWh}$, this value being equal to $10 \%$ of the existing production. 
Since it doesn't exist a reference regulation to carry out this study many situations got by combining the following four variables have been suggested:

- Unit Cost of fuel $\left(C_{f u e l}\right)$ : equal to the basic price, that is $0,33 € / l$, or to $1.5-2$ times this price;

- State incentives $\left(k_{s i}\right)$ : equal to $75 \%, 50 \%, 25 \%$ or $0 \%$ of the investment cost;

- Decrease in the technology cost $\left(k_{t}\right)$ : equal to $100 \%$, $75 \%, 50 \%$ or $25 \%$ of the existing market price ( $8000 € / \mathrm{kWp}$ with reference to the national notices and prices published by ENEA);

- Unit Cost of Green Certificates $\left(C_{G C}\right)$ : equal to the basic price, that is $0.0841 € / \mathrm{kWh}$, or to twice or three times the same (the basic price has been fixed on the basis of the prices of 2002 established by the Operator of the National Transmission Network).

The variables described have been used to determine 33 different market situations and so to practice the simulations. The program has determined economic functions and indices for all 33 situations. Only 12 situations are given, as an example, in Table I.

TABLE I. Situations supposed

\begin{tabular}{|r|r|r|r|r|}
\hline Situations & $\begin{array}{l}\text { Unit cost of } \\
\text { fuel }\end{array}$ & $\begin{array}{l}\text { Decrease in } \\
\text { technology } \\
\text { cost }\end{array}$ & $\begin{array}{l}\text { State in- } \\
\text { centives }\end{array}$ & $\begin{array}{l}\text { Unit cost of } \\
\text { green } \\
\text { certificates } \\
\mathbf{C}_{\mathbf{G C}}\end{array}$ \\
\hline & $\mathbf{C}_{\text {fuel }}$ & \multicolumn{1}{c|}{$\mathbf{k}_{\mathbf{t}}$} & $\mathbf{k}_{\text {si }}$ & \multicolumn{1}{c|}{$€ / \mathrm{kWh}$} \\
\hline 0 & 0.33 & $100 \%$ & $0 \%$ & 0.0841 \\
\hline 1 & 0.33 & $75 \%$ & $0 \%$ & 0.0841 \\
\hline 2 & 0.33 & $50 \%$ & $0 \%$ & 0.0841 \\
\hline 3 & 0.33 & $25 \%$ & $0 \%$ & 0.0841 \\
\hline 4 & 0.33 & $100 \%$ & $75 \%$ & 0.0841 \\
\hline 5 & 0.33 & $75 \%$ & $75 \%$ & 0.0841 \\
\hline 6 & 0.33 & $50 \%$ & $75 \%$ & 0.0841 \\
\hline 13 & 0.495 & $100 \%$ & $0 \%$ & 0.16 \\
\hline 17 & 0.495 & $100 \%$ & $75 \%$ & 0.16 \\
\hline 20 & 0.495 & $100 \%$ & $50 \%$ & 0.16 \\
\hline 23 & 0.66 & $100 \%$ & $0 \%$ & 0.24 \\
\hline 24 & 0.66 & $75 \%$ & $0 \%$ & 0.24 \\
\hline 27 & 0.66 & $100 \%$ & $75 \%$ & 0.24 \\
\hline & & & & \\
\hline
\end{tabular}

\section{B. Analysis of some situations}

Figures 5, 6 and 7 show the trend of the Net Present Value as a function of the interest rate for some situations taken into exam. Fig. 8 and Fig. 9 show the value of the Pay Back Period for all 33 situations.

1) Situation zero. As for situation zero the Authors have fixed that the price of the fuel, the cost of the Green Certificates and the cost of the photovoltaic technology are equal to the basic values, while the state incentives are equal to $0 \%$ of the total amount. The NPV curve we obtain is completely negative, which means that the investment is not profitable (see Fig. 5).

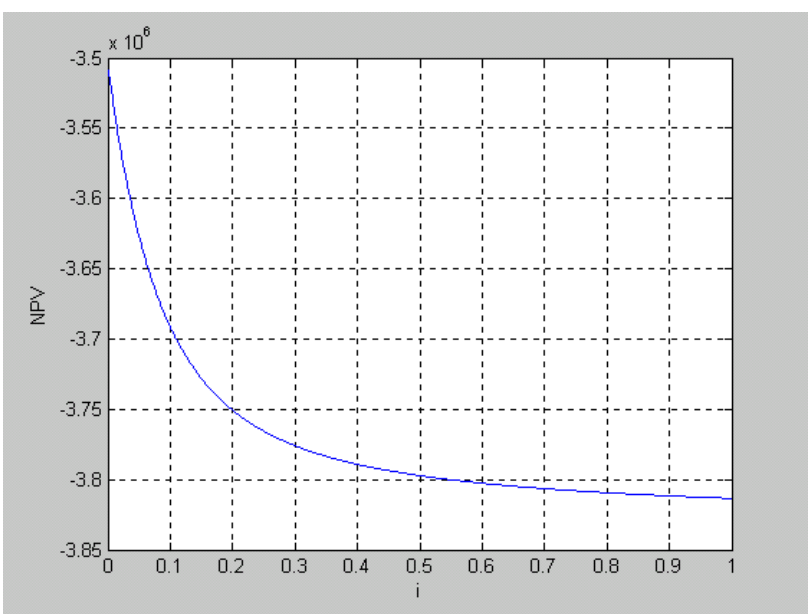

Fig. 5. Trend of the NPV function for situation zero

2) Situation 5. As for situation 5, the price of fuel, technology and green certificates have been fixed by the Authors at the basic price, while the percentage of state incentives is $75 \%$ of the investment cost, this value being in agreement with the national notices. Fig. 6 shows that, in the first part of the trend, the NPV function is positive and so, for the values of the interest rate included between 0 and $1 \%$, the evaluation of the economic indices could be useful.

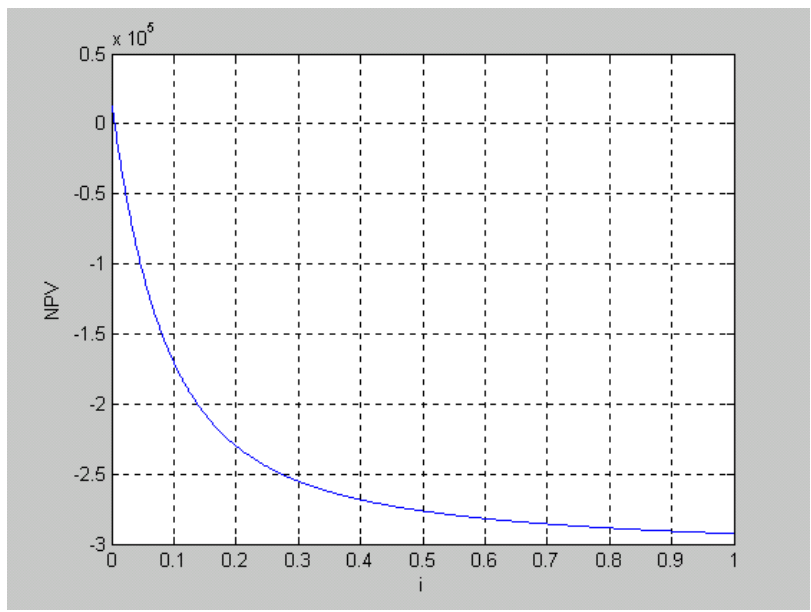

Fig. 6. Trend of the NPV function for situation 5

3) Situation 6. As for situation 6 the Authors have fixed that the price of fuel and Green Certificates is equal to the basic price, while the percentage of state incentives has been taken as equal to $75 \%$ and the cost of the technology has been reduced by $50 \%$. In this case the NPV curve is positive for the values of the interest rate included between 0 and 5\% (see Fig. 7). This shows there is an economic, financial gain in the investment (remember that the interest rate $i$ recommended by the European Community for technological investments is $4 \%)$. 


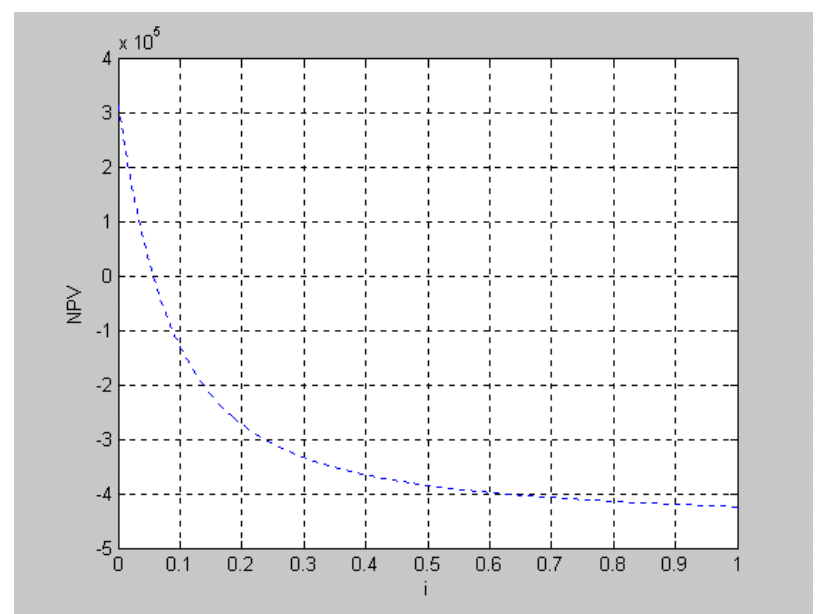

Fig. 7. Trend of the NPV function for situation 6

Fig. 8 gives the values of the Pay Back Periods calculated by taking into account only the saving of fuel $\left(S_{f}\right)$ for all the 33 different situations.

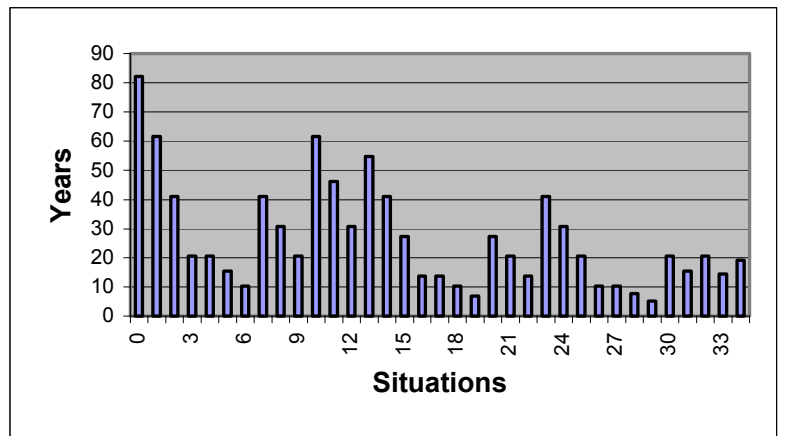

Fig. 8. Pay Back Periods of all situations examined calculated by taking into account only the saving of fuel $\left(S_{f}\right)$

Fig. 9 gives the values of the Pay Back Periods when also the saving $S_{G C}$ due to the non-purchase of the green certificates is taken into account.

You can say that the values of the Pay Back Periods further decrease with respect to Fig. 8, which means that, in this case, the investment is even more favorable. This is the case in which the producer can, in the future, be obliged by the Italian law-maker to use renewable sources or, as an alternative, to purchase Green Certificates.

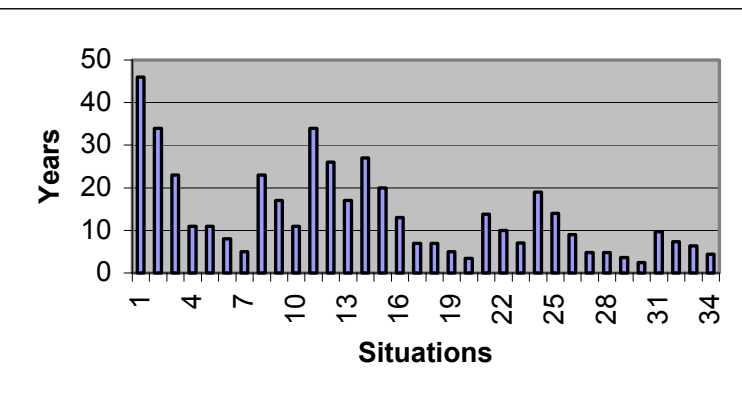

Fig. 9. Pay Back Periods of all situations examined calculated by taking into account both the saving of fuel $\left(S_{f}\right)$ and the saving due to the non-purchase of the Green Certificates $\left(S_{G C}\right)$
As you can see the PBP values change according to the situations examined. In particular, as for situations 5 and 6 , the time required for recovering the invested capital is acceptable if it is compared with the working life of these plants, fixed at 20 years.

\section{Conclusions}

This study has shown that, if existing prices of the photovoltaic technology and lack of public economic incentives are taken into account, the investment does not turn out to be economically profitable. However, the various situations taken into account have pointed out that, if we assume that the working life of the electric power plant is equal to twenty years and if there are adequate public economic incentives, there is a good margin of economic advantage.

In conclusion the Authors think that they have defined a tool which can be useful to the Italian law-maker for estimating the value of the state incentives to allocate to small producers of electric energy, these incentives having to be obviously correlated with the technology costs. In this way the growth of the photovoltaic technology can be favored, thus complying with the Kyoto Protocol.

\section{References}

[1] D.Lgs n.79, Attuazione della direttiva 96/92/CE recante norme comuni per il mercato interno dell'energia elettrica. GU n.75 del 31/03/1999, Italy, pp. 8-22.

[2] Legge del 09/01/1991 n. 10, Norme in materia di uso razionale dell'energia, di risparmio energetico e di sviluppo delle fonti rinnovabili di energia. GU n. 13 del 16/01/1991, Italy.

[3] Bando Ministero dell'Ambiente, Servizio inquinamento atmosferico e le industrie a rischio, Programma Isole Minori, Italy 2000.

[4] F. Groppi and C. Zuccaio, Impianti solari fotovoltaici a norme CEI, Utet (Italy), pp.107-149.

[5] M. Imamura et alii, Photovoltaic System technology, European Handbook, 1992.

[6] M. Guerra, Gli impianti fotovoltaici e il loro dimensionamento, lectures note, ENEA - Experimental Area Monte Aquilone, Manfredonia (FG), Italy, 2002, pp. 36-40.

[7] F. Apicella, Gli impianti fotovoltaici nella generazione diffusa la normativa elettrica negli aspetti di esercizio, protezione e sicurezza, lectures note, ENEA - Experimental Area Monte Aquilone, Manfredonia (FG), Italy, 2001, pp. 1-35.

[8] Norma UNI 10349, Riscaldamento e raffrescamento degli edifici. Dati climatici, april 1994.

[9] Norma UNI 8477 parte $1^{a}$, Energia solare. Calcolo degli apporti energetici in edilizia. Valutazione dell'energia raggiante ricevuta, may 1983.

[10] Norma UNI 8477 parte $2^{\text {a }}$, Energia solare. Calcolo degli apporti per applicazioni in edilizia. Valutazione degli apporti ottenibili mediante sistemi attivi o passivi, december 1985.

[11] G. Chiassino, Matematica finanziaria, Cacucci, Bari (Italy), 2002.

[12] A. Borello, Il business plan, McGraw-Hill, Milano (Italy), 2002. 